\title{
Nursing education in Africa: Year of the nurse and midwife
}

Nursing science is a caring science with discipline-specific knowledge that focuses on the human-health-environment interaction articulated in nursing frameworks and theories reflected in specific nursing paradigms aligned with nursing's unique phenomenon of concern. ${ }^{[1]}$ Unpacking this understanding of nursing science brings to the fore the fundamental focus of nursing, which is usually not clear to nurses and their interprofessional colleagues.

Globally, the last 50 years have seen tremendous advancement in nursing science. Such advancements steered the transition of nursing from being an occupation, through to being a vocation and ultimately a profession. However, the majority of preregistration nursing programmes in Africa are still skills-driven vocational programmes, where nursing students are perceived as a 'pair of hands' in healthcare environments. ${ }^{[2]}$ Nursing students in these programmes learn a limited set of skills, with minimal theoretical knowledge to support critical thinking and clinical reasoning, which are essential competencies for healthcare practitioners in the 21 st century.

Nevertheless, Africa has also witnessed developments in nursing education programmes. These include the introduction of preregistration nursing degree programmes, postgraduate nursing programmes, including PhDs, eLearning nursing programmes and curricular reforms, such as the introduction of competency-based curricula. ${ }^{[3]}$ These nursing education-related developments are aimed at improving the quality of nursing and the overall contribution of the nursing profession to the health of communities in Africa. It is essential that developments in nursing education programmes in Africa align with nursing science and educational theory.

Evidence from some African contexts points out disparities in the enactment of the developments in nursing education programmes. ${ }^{[4]}$ Teaching and learning activities for nursing students enrolled in 'reformed' programmes mirror their ancestor programmes. Assessment of student learning still focuses on a limited set of skills, and the clinical learning environment continues to be hostile and not ready for student learning.
The limitations of nurse educators, poor monitoring systems, poor support structures and poor regulation of nursing education programmes in Africa depreciate the value of developments in such programmes. ${ }^{[5]}$ The developments in nursing programmes eventually become meaningless, superficial paperbased initiatives with no true transformation in the quality of nurses and their contribution to healthcare.

The World Health Organization (WHO) declared 2020 as the 'Year of the Nurse and Midwife. Part of the initiatives during this year include elevating the status of nursing and its contribution to healthcare. The African Journal of Health Professions Education will be publishing a special focus issue on nursing and midwifery education in Africa. We envision that this issue will present debates, innovations and outcomes of scholarly research in nursing and midwifery education from nursing scholars in Africa. Papers are invited from Africa, focusing on undergraduate, postgraduate and continuing professional development of nurses and midwives on the African continent.

\section{Champion N Nyoni}

Guest Editor: Special focus issue on nursing and midwifery education

School of Nursing, Faculty of Health Sciences, University of the Free State, Bloemfontein, South Africa

nyonic@ufs.ac.za

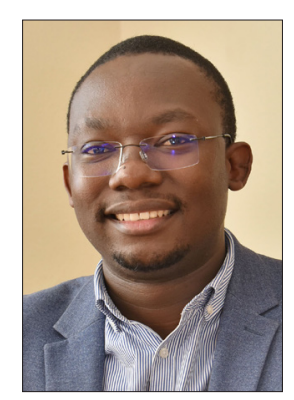

1. BarrettE. Again, what is nursing science? Nurs Sci Q 2017;30(2):129-133. https://doi.org/10.1177/0894318417693313 2. Bvumbwe T, Mtshali N. Nursing education challenges and solutions in Sub Saharan Africa: An integrative review. BMC Nurs 2018;17(1):3. https://doi.org/10.1186/s12912-018-0272-4 3. Muraraneza C, Mtshali NG, Mukamana D. Issues and challenges of curriculum reform to competency-b
curricula in Africa: A meta-synthesis. Nurs Heal Sci 2017;19(1):5-12. https://doi.org/10.1111/nhs.12316 curricula in Africa: A meta-synthesis. Nurs Heal Sci 2017;19(1):5-12. https://doi.org/10.1111/nhs. 12316
Nyoni CN, Botma Y. Implementing a competency-based midwifery programme in Lesotho: A gap analysis. 4. Nyoni CN, Botma Y. Implementing a competency-based midwifery progra
Nurse Educ Pract 2019;34:72-78. https://doi.org/10.1016/.jnepr.2018.11.005

Nurse Educ Pract 2019;34:72-78. https://doi.org/10.1016/j.nepr.2018.11.005 5. Nyoni CN, Botma Y. Sustaining a newly implemented competency based-midwifery prof
Emerging issues. Midwifery 2018;59:115-117. https://doi.org/10.1016/j.midw.2018.01.015

Afr J Health Professions Educ 2020;12(1):3. https://doi.org/10.7196/AJHPE.2020.v12i1.1327 